\title{
Serum glial cell line-derived neurotrophic factor levels and postoperative cognitive dysfunction after surgery for rheumatic heart disease
}

Xiaoxia Duan, MS, ${ }^{\mathrm{a}, \mathrm{b}}$ Tao Zhu, MD, ${ }^{\mathrm{a}}$ Chan Chen, MD, ${ }^{\mathrm{a}}$ Guanpeng Zhang, BS, ${ }^{\mathrm{c}}$ Junhui Zhang, MD, ${ }^{\mathrm{d}}$ Lin Wang, MS, ${ }^{\mathrm{e}}$ Luye Zhang, BS, ${ }^{\mathrm{e}}$ Maohua Wang, $\mathrm{MD},{ }^{\mathrm{b}}$ and Xiaobin Wang, $\mathrm{MS}^{\mathrm{b}}$

\section{ABSTRACT}

Objective: Postoperative cognitive dysfunction is an important complication of cardiac surgery with poor outcomes. Serum glial cell line-derived neurotrophic factor levels are decreased in patients with Alzheimer's disease, but the association between glial cell line-derived neurotrophic factor levels and postoperative cognitive dysfunction is poorly understood. The present study aimed to investigate the prognostic value of postoperative serum glial cell linederived neurotrophic factor levels to predict postoperative cognitive dysfunction in patients with rheumatic heart disease undergoing heart valve replacement.

Methods: This was a prospective observational study of 80 patients undergoing elective heart valve replacement surgery from June 2015 to June 2016 at the Affiliated Hospital of Southeast Medical University. Cognitive functions were assessed 1 day before and 7 days after surgery. Serum glial cell line-derived neurotrophic factor levels were measured by an enzyme-linked immunosorbent assay before (T1) and 1 (T2), 2 (T3), and 7 (T4) days after surgery. Perioperative parameters were evaluated to assess the relationship between glial cell line-derived neurotrophic factors and postoperative cognitive dysfunction.

Results: Postoperative cognitive dysfunction was identified in 38 patients $(47.5 \%) 7$ days after surgery. Average glial cell line-derived neurotrophic factor levels at 2 and 7 days after surgery in the postoperative cognitive dysfunction group were lower than in the nonpostoperative cognitive dysfunction group at the same time points $(P<.001) . \Delta$ Glial cell line-derived neurotrophic factor (T1-T3) and $\Delta$ glial cell line-derived neurotrophic factor (T1-T4) were identified as good predictors of postoperative cognitive dysfunction with threshold for postoperative cognitive dysfunction detection of 49.10 and 60.90, respectively.

Conclusions: The perioperative glial cell line-derived neurotrophic factor levels in patients with postoperative cognitive dysfunction were lower than in patients without postoperative cognitive dysfunction. Glial cell line-derived neurotrophic factor could be an effective predictor for the occurrence of postoperative cognitive dysfunction. The results reveal a potentially important role of decreased glial cell line-derived neurotrophic factor levels in postoperative cognitive dysfunction, with possible treatment targets. (J Thorac Cardiovasc Surg 2018;155:958-65)

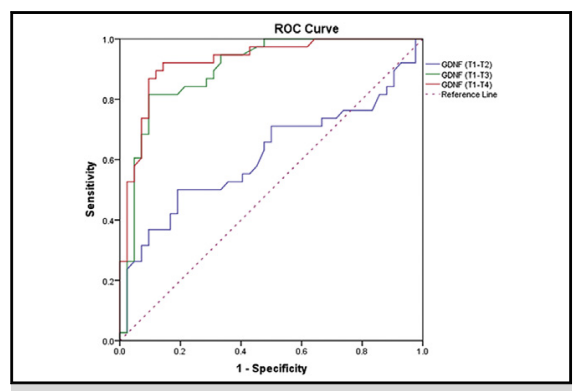

Receiver operating characteristic analysis of the average $\triangle \mathrm{GDNF}$ at $\mathrm{T} 2, \mathrm{~T} 3$, and $\mathrm{T} 4$ compared with $\mathrm{T} 1$.

\section{Central Message}

Perioperative GDNF levels could be an effective predictor for the occurrence of POCD.

\section{Perspective}

Although POCD is a common complication after cardiac surgery, the pathophysiology of POCD is poorly understood. Intraoperative GDNF levels of patients with POCD are lower than in patients without POCD. Perioperative GDNF levels are effective predictors of POCD in patients undergoing cardiac surgery. The results provide a new insight into the diagnosis and possible treatment targets for POCD.

See Editorial Commentaries pages 966 and 968.

\footnotetext{
From the a Department of Anesthesiology and Translational Neuroscience Center, West China Hospital, Sichuan University, Chengdu; Departments of ${ }^{\mathrm{b}}$ Anesthesiology and ${ }^{c}$ Electrocardiogram, the Affiliated Hospital of Southwest Medical University, and ${ }^{\mathrm{d}}$ Department of Epidemiology and Health Statistics, Public Health School, Southwest Medical University; and ${ }^{\mathrm{e} D e p a r t m e n t ~ o f ~ P s y c h i a t r y, ~ t h e ~ A f f i l i a t e d ~ H o s-~}$ pital of Southwest Medical University, Luzhou, China.

Funded by the Foundation of the Health and Family Planning Commission of Sichuan Province (150077), the South West Medical University (2014QN-083), and the Affiliated Hospital of South West Medical University, National Natural Science Foundation of China $(81671062,81500937,81271478,815410909)$ and China Scholarship Council Support (201608515124).
}

Clinical Trial Registry Number: ChiCTR-IPD-15006534

Received for publication Aug 21, 2016; revisions received June 29, 2017; accepted for publication July 25, 2017; available ahead of print Sept 13, 2017.

Address for reprints: Tao Zhu, MD, Department of Anesthesiology and Translational Neuroscience Center, West China Hospital, Sichuan University, No. 37 Guoxue Xiang, Wuhou District, Chengdu 610041, Sichuan, China (E-mail: xwtao_zhu@ yahoo.com). 0022-5223/\$36.00

Copyright (C) 2017 Published by Elsevier Inc. on behalf of The American Association for Thoracic Surgery

http://dx.doi.org/10.1016/j.jtcvs.2017.07.073 


\section{Abbreviations and Acronyms}

ACT = activated clotting time

AS = Alzheimer's disease

$\mathrm{CSF}=$ cerebrospinal fluid

GDNF $=$ glial cell line-derived neurotrophic factor

MMSE $=$ Mini-Mental State Examination

POCD $=$ postoperative cognitive dysfunction

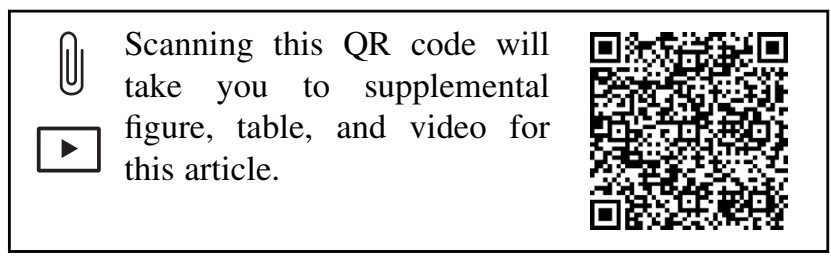

Rheumatic heart disease is a serious condition that often requires surgical valve replacement. ${ }^{1}$ These surgeries may involve extracorporeal circulation, depending on the exact procedure selected by the surgeons. ${ }^{1}$ Although surgical techniques and brain-protection strategies have been improved, postoperative cognitive dysfunction (POCD) is a common complication after cardiac surgery and extracorporeal circulation, ${ }^{2-5}$ especially among patients with rheumatic heart disease. ${ }^{6,7}$ The occurrence of POCD has been associated with multiple adverse outcomes, including longer hospital stay, ${ }^{8}$ increased mortality, ${ }^{9}$ and decreased long-term quality of life. ${ }^{10}$ Currently, it is not possible to classify a patient with POCD using standard classification criteria, such as the International Statistical Classification of Disease 9th Revision or the Diagnostic and Statistical Manual of Mental Disorders IV. Nevertheless, POCD is typically defined as a significant and persistent change in mental status as assessed by poorer than expected performance on postoperative neurocognitive tests. ${ }^{11}$

Determining the causes of POCD is important to identify strategies for its prevention. Despite a number of studies, the pathophysiology of POCD remains poorly understood. Descriptive studies have identified older age and lower education levels as being associated with an increased risk of $\mathrm{POCD},{ }^{12}$ but these factors also predict cognitive decline in population studies without surgery. ${ }^{13}$ POCD is defined as a significant dysfunction in cognitive performance and likely has a pathogenesis similar to that of Alzheimer's disease (AD). ${ }^{14}$

Glial cell line-derived neurotrophic factor (GDNF) is a protein that promotes the survival of many types of neurons. ${ }^{15}$ GDNF levels are low in patients with AD. ${ }^{8,16}$ Decreased serum GDNF levels in patients with AD could be related to altered brain function. ${ }^{17}$ Therefore, GDNF could be a marker for POCD in patients undergoing cardiac surgery.
Therefore, the present study aimed to evaluate the relationship between postoperative serum GDNF levels and POCD and to investigate the ability of postoperative serum GDNF levels to predict POCD in patients undergoing heart valve replacement surgery (Video 1).

\section{PATIENTS AND METHODS \\ Patients}

This was a prospective observational study of patients with rheumatic heart disease undergoing elective heart valve replacement between June 2015 and June 2016 at the Affiliated Hospital of Southeast Medical University, China. The inclusion criteria were (1) 20 to 70 years of age; (2) confirmed rheumatic heart disease; and (3) indications for heart valve replacement. The exclusion criteria were (1) Mini-Mental State Examination (MMSE) score less than 24 before surgery; (2) history of psychiatric or neurological disorders, cardiothoracic surgery, or any severe visual or auditory disorders; (3) refusal to participate or cannot speak or understand Chinese language; (4) delirious state; or (5) missing biomarker measurements. The study protocol was approved by the Affiliated Hospital of Southwest Medical University Ethics Committee (KY2016003). The study was registered at the Chinese Clinical Trial Registry (ChiCTR-IPD-15006534). A written informed consent was obtained from the patients or their relatives before study enrollment.

\section{Clinical Assessment}

On admission, demographic factors such as age, gender, education, body mass index, and the American Society of Anesthesiologists status were recorded. Chronic smoking was defined as smoking more than 20 cigarettes per day for 1 month. Alcoholism was defined as consumption of an equivalent of $150 \mathrm{~mL}$ of alcohol per week. The New York Heart Association classification was determined by a cardiologist. The possible perioperative confounding factors, such as the duration of on-pump time, duration of aorta crossclamping, duration of recovery temperature, duration of surgery, and amount of transfused blood, were recorded.

\section{Anesthesia}

The routine vital signs of the patients were monitored, and the patient received oxygen inhalation $(6 \mathrm{~L} / \mathrm{min})$. Anesthesia induction included intravenous injection of penehyclidine hydrochloride $0.01 \mathrm{mg} / \mathrm{kg}$, midazolam 0.03 to $0.05 \mathrm{mg} / \mathrm{kg}$, fentanyl 8 to $10 \mu \mathrm{g} / \mathrm{kg}$, vecuronium $0.15 \mathrm{mg} / \mathrm{kg}$, and etomidate 2 to $3 \mathrm{mg} / \mathrm{kg}$. After anesthesia induction and tracheal intubation, the patient underwent catheterization of the left radial artery and right internal jugular vein. Invasive arterial blood pressure and central vein pressure were continually monitored. Anesthesia maintenance included intravenous pump of midazolam $(0.01-0.015 \mathrm{mg} / \mathrm{kg} / \mathrm{min})$, vecuronium (0.06-0.08 $\mathrm{mg} / \mathrm{kg} / \mathrm{min})$, and fentanyl $(8-10 \mu \mathrm{g} / \mathrm{kg} / \mathrm{min})$. Generally, the doses of the drugs was maintained according to the patient's body weight, but the dose of narcotic drug was adjusted according to the patient's conditions during surgery, such as the amount of blood loss, the volume of extracorporeal circulation perfusion, and the changes in vital signs of patients. The doses of the drugs were usually progressively decreased during surgery, and the doses were increased as the patient's body temperature and metabolism increased. Occasionally, to adjust the depth of anesthesia, a single dose of midazolam, fentanyl, vecuronium, and etomidate could be added $(0.03-0.05 \mathrm{mg} / \mathrm{kg}, 8-10 \mu \mathrm{g} / \mathrm{kg}, 0.15 \mathrm{mg} / \mathrm{kg}$, and $2-3 \mathrm{mg} / \mathrm{kg}$, respectively). Vasoactive drugs (eg, dopamine, dobutamine, sodium nitroprusside, and epinephrine) were pumped through a central venous catheter according to the intraoperative conditions and surgical procedure.

\section{Cardiopulmonary Bypass}

The priming solution was lactated Ringer's solution and polygeline injection; the ratio of crystalloid osmotic pressure/colloid osmotic pressure 


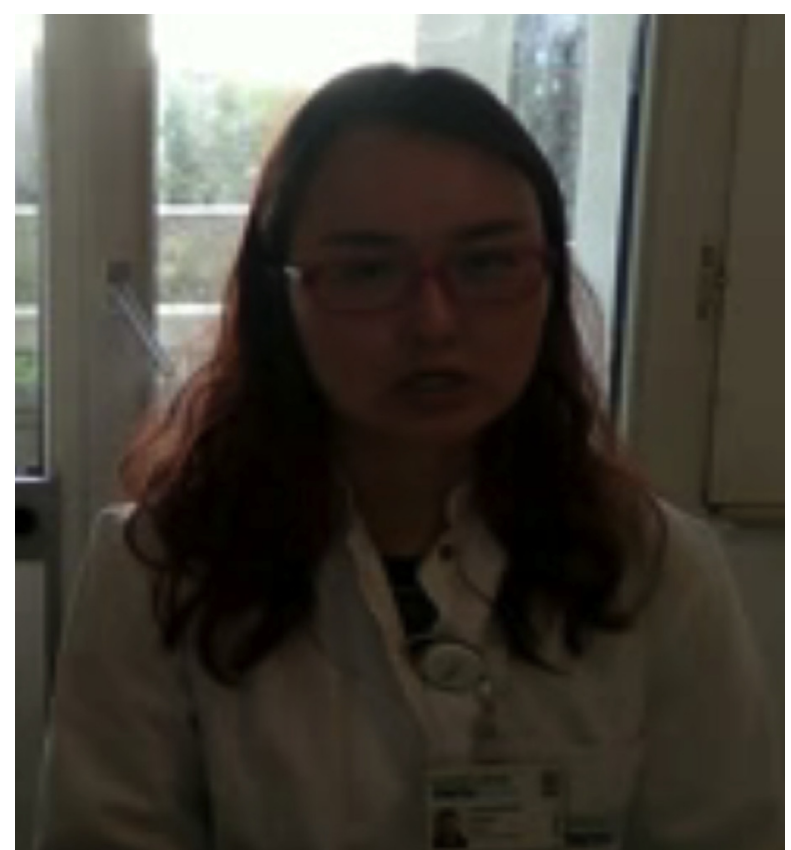

VIDEO 1. The video explains the importance of the research. Video available at: http://www.jtcvsonline.org/article/S0022-5223(17)31762-2/fulltext.

ranged from 0.4 to 0.6 to 1 . Heparin $(15 \mathrm{mg})$ was added to the priming solution. After the completion of the thoracotomy hemostasis, the patient was intravenously injected with $4 \mathrm{mg} / \mathrm{kg}$ heparin through the central venous catheter. The activated clotting time (ACT) value was maintained at more than 600 seconds. During cardiopulmonary bypass, the ACT values were monitored once every hour. If necessary, 1 to $2 \mathrm{mg} / \mathrm{kg}$ heparin was added to maintain ACT greater than 600 seconds. After aorta crossclamping, cold cardioplegic solution with oxygenated blood $\left(4^{\circ} \mathrm{C}\right)$ (oxygenated blood:cardioplegia at 4:1) was infused into the aortic root using a perfusion pump once every 30 minutes. At first, the perfusion volume was 5 to $20 \mathrm{~mL} / \mathrm{kg} / \mathrm{min}$, which could achieve cardiac arrest. After that, each perfusion volume was half of that of the first time. During cardiopulmonary bypass, the esophagus temperature was maintained at $28^{\circ} \mathrm{C}$ to $32^{\circ} \mathrm{C}$. The blood volume was moderately diluted (hematocrit of $20 \%-25 \%$ ). The perfusion was in the range of 2.0 to $2.8 \mathrm{~L} / \mathrm{min} / \mathrm{m}^{2}$. The mean arterial pressure was controlled to 50 to $80 \mathrm{~mm} \mathrm{Hg}$. Vasoactive drugs were used during surgery to maintain the relative stability of hemodynamics, blood gas, and electrolytes.

\section{Surgery}

The surgery was performed using a routine approach. Heparin ( $4 \mathrm{mg} / \mathrm{kg}$ ) was pumped into the central venous catheter. When ACT was greater than 400 seconds, aortic catheterization was established at the ascending aortic root. Coronary perfusion cannula, superior and inferior vena catheterization, and left ventricular drainage tubes were established. Cardiopulmonary bypass started when ACT was greater than 480 seconds. The body temperature was reduced during cardiopulmonary bypass, and the superior and inferior vena cava were blocked. When the body temperature was reduced to $32^{\circ} \mathrm{C}$, the aorta blood flow was blocked using an aortic clamp. Cold cardioplegic solution with oxygenated blood $\left(15-20 \mathrm{~mL} / \mathrm{kg} 4^{\circ} \mathrm{C}\right)$ (oxygenated blood:cardioplegia ratio of 4:1) was infused via the coronary perfusion cannula at the aortic root. Ice was melted on the surface of heart. After replacement, the temperature was resumed, and the heart incisions were sutured. The surgery bed was placed in the head-down position to open the superior and inferior vena cava. The aortic block clamp was open, and the heart beat was resumed, assisted with electric shock if needed. Cardiopulmonary bypass was still used to assist perfusion. When the heart function indexes recovered to normal, the body temperature was elevated and resumed, and the normal circulation was resumed. Protamine (1.2:1) was intravenously infused through the central vein to neutralize the heparin.

\section{Neurocognitive Evaluation}

One day before and 7 days after surgery, the neuropsychologic tests were conducted by the trained physician to characterize POCD. The protocol consisted of the MMSE, Digit Span Test, Clock Drawing Test, Symbol Digit Modalities Test, and Trail Making Test A, which primarily focus on learning, memory, attention, concentration, and executive function.

To determine a normal reference value of cognitive functions, 20 healthy subjects without operation were recruited as a control group and matched for age, gender, and education level. Cognitive functions were assessed twice at 7-day intervals, and the standard deviation of the baseline score was calculated. Learning effects, which exist in reduplicative neuropsychologic tests, ${ }^{18}$ were also calculated as the mean variation of the second assessments from baseline.

The patients in the study group were divided into the non-POCD and POCD groups according to the International Study of Postoperative Cognitive Dysfunction guidelines. ${ }^{18}$ Specifically, the baseline score and learning effect were subtracted from each neuropsychologic test score, and then the difference was divided by the standard deviation of the baseline score in the control group. The magnitude of the result was called the $Z$ score, and the patients with at least $2 \mathrm{Z}$ scores greater than 1.96 were assigned to the POCD group. ${ }^{19}$

\section{Glial Cell Line-Derived Neurotrophic Factor Immunoassay}

The patient's blood samples were obtained (between 7 and $8 \mathrm{Am}$ ) before surgery and 1,2, and 7 days after the surgery. The collected samples were immediately placed on ice, centrifuged within 30 minutes after sampling, and stored at $-18^{\circ} \mathrm{C}$. Serum GDNF levels were measured using an enzyme-linked immunosorbent assay kit $(20150707 \mathrm{H}$, ChengLing Biocorporation, Beijing, China) according to the manufacturer's instructions. Samples were diluted with Dulbecco's phosphate-buffered saline. All standards and samples were measured in duplicate. According to the manufacturer's instructions, the detection limit for GDNF was $37.5 \mathrm{pg} / \mathrm{mL}$. Eighty microliters of serum were added to each well. The dilution factor was 1:3. After dilution, an acid treatment procedure was performed to enhance the total GDNF concentration by disrupting the interaction between the carrier protein or receptor and ligand. ${ }^{20}$ Previous tests comparing plasma and serum samples with and without acidification consistently showed higher concentrations of total GDNF in acid-treated serum samples. After acid treatment, the dilution factor was 1:3.3. Samples were measured in duplicate.

\section{Statistical Analysis}

Categoric variables were presented as frequencies and analyzed using the chi-square test or the Fisher exact test, as appropriate. Normal distribution of continuous data was tested using the Kolmogorov-Smirnov test. Normally distributed continuous data were presented as mean \pm standard deviation and analyzed using the Student $t$ test. Non-normally distributed continuous data were presented as median (range) and analyzed using the Wilcoxon test. Baseline and perioperative variables were evaluated for univariable association with POCD. Repeated measures were evaluated with repeated-measure analysis of variance. Variables with $P$ less than .10 in univariable analyses were included in a multivariable logistic regression model to determine the independent predictors of POCD; results were presented as odds ratio and $95 \%$ confidence interval. The receiver operating characteristic approach was 
TABLE 1. General characteristics and cognitive functions of participants from study and control groups at baseline

\begin{tabular}{lccr}
\hline $\begin{array}{c}\text { General characteristics } \\
\text { and cognitive } \\
\text { function scores }\end{array}$ & $\begin{array}{c}\text { Study group } \\
(\mathbf{n = 8 0})\end{array}$ & $\begin{array}{c}\text { Control group } \\
(\mathbf{n}=\mathbf{2 0})\end{array}$ & $\begin{array}{c}\boldsymbol{P} \\
\text { value }\end{array}$ \\
\hline Age $(\mathrm{y})$ & $56.7 \pm 5.3$ & $55.5 \pm 6.1$ & .392 \\
Male & $36(45.0 \%)$ & $7(35.0 \%)$ & .419 \\
\hline BMI $\left(\mathrm{kg} / \mathrm{m}^{2}\right)$ & $26.3 \pm 1.4$ & $25.7 \pm 1.0$ & .098 \\
\hline $\begin{array}{l}\text { Education }(\text { higher than } \\
\text { middle school) }\end{array}$ & $28(35.0 \%)$ & $11(55.0 \%)$ & .101 \\
\hline Baseline MMSE scores & $27(25,30)$ & $28.5(27-30)$ & $<.001$ \\
\hline Baseline DST scores & $15(11,16)$ & $14(11-16)$ & .306 \\
\hline Baseline CDT scores & $3(2,3)$ & $3(2-3)$ & .832 \\
\hline Baseline SDMT scores & $33(25,35)$ & $31.5(27-35)$ & .061 \\
\hline Baseline TMT-A scores & $41(35,42)$ & $42(33-44)$ & .078 \\
\hline
\end{tabular}

$B M I$, Body mass index; MMSE, Mini-Mental State Examination; DST, Digit Span Test; $C D T$, Clock Drawing Test; SDMT, Symbol Digit Modalities Test; TMT-A, Trail Making Test A.

used to determine the best threshold of GDNF values to predict POCD, as determined using the area under the curve and $95 \%$ confidence interval. All statistical analyses were performed with SPSS 22.0 (SPSS Inc, Chicago, Ill) and Excel 2007 (Microsoft Inc, Redmond, Wash).

\section{RESULTS}

A total of 80 patients were included (Figure E1). As illustrated in Table 1, no difference was observed between the 2 groups in terms of age, gender, body mass index, and education level. When comparing the cognitive functions at baseline between the study and healthy control groups (Table 1), no significant differences were observed for Digit Span Test, Clock Drawing Test, Symbol Digit Modalities Test, and Trail Making Test A scores, whereas the MMSE scores were significantly lower in the study group compared with the healthy control group $(27.1 \pm 1.0$ vs $28.4 \pm 0.9 ; P<.001)$.

According to the International Study of Postoperative Cognitive Dysfunction criterion, POCD occurred in 38 patients (47.5\%). Table 2 presents the clinical characteristics of the non-POCD and POCD groups. The average GDNF levels before and 1 day after surgery showed no differences between the 2 groups, whereas the average GDNF levels at 2 and 7 days after surgery in the POCD group were lower than those in the non-POCD group $(P<.001$, Table 2, Figure 1$)$. The average GDNF levels were decreased at 1,2 , and 7 days after surgery in the POCD group $(P<.001)$, and these levels were decreased at 2 and 7 days after surgery in the non-POCD group $(P<.001$, Figure 1$)$.

Duration of the aorta crossclamping, duration of surgery, and amount of transfused blood were significantly different between the POCD and non-POCD groups $(P=.026$, $P=.034$, and $P=.009$, respectively) (Table 2), indicating that these factors could influence the occurrence of POCD in patients undergoing heart valve replacement surgery. There were no differences in cardiovascular risk factors (arrhythmia, hypertension, diabetes mellitus, chronic smoking, and alcoholism) between the POCD and non-POCD groups (Table 2).

When comparing the cognitive functions between the POCD and non-POCD groups (Table 3), significant differences were observed for the MMSE, Digit Span Test, and Clock Drawing Test scores between T1 and T4 $(P<.01)$.

The results of the multivariable logistic regression analysis showed that age and $\triangle \mathrm{GDNF}$ (T1-T4) were independently associated with POCD (Table E1). The time course of the GNDF levels showed that the GNDF levels were significantly lower in the POCD group than in the non-POCD group at T3 and T4 (both $P<.001$ ).

The receiver operating characteristic curves (Figure 2) present the predictive performance of $\triangle \mathrm{GDNF}$ (the change in GDNF at T2, T3, and T4 compared with the GDNF at T1) for the occurrence of POCD. The areas under the curve were $0.614(P>.05), 0.898(P<.01)$, and $0.925(P<.01)$ for $\triangle \mathrm{GDNF}(\mathrm{T} 1-\mathrm{T} 2), \triangle \mathrm{GDNF}(\mathrm{T} 1-\mathrm{T} 3)$, and $\triangle \mathrm{GDNF}(\mathrm{T} 1-\mathrm{T} 4)$, respectively, suggesting that $\triangle \mathrm{GDNF}(\mathrm{T} 1-\mathrm{T} 3)$ and $\triangle \mathrm{GDNF}(\mathrm{T} 1-\mathrm{T} 4)$ could be predictors of POCD. The $\triangle$ GDNF (T1-T3) threshold for POCD detection was 49.10 , with a sensitivity and specificity of $81.6 \%$ and $90.5 \%$, respectively. The $\triangle \mathrm{GDNF}$ (T1-T4) threshold for POCD detection was 60.90 , with a sensitivity and specificity of $92.1 \%$ and $85.7 \%$, respectively.

\section{DISCUSSION}

The present study suggests that for patients undergoing valve replacement surgery, the reduction in the serum levels of GDNF in patients with POCD was greater than in patients without POCD, suggesting that the GDNF level could be a predictor for the diagnosis of POCD.

POCD is an important complication of cardiac surgery, and the associated neurocognitive dysfunction can affect quality of life and lead to social, functional, emotional, and financial problems. Questionnaires are commonly used for the diagnosis of POCD, which requires trained physician and patient cooperation. Biochemistry examination could be easier than questionnaires for patients with depression, delirium, or hearing disorders.

Until now, different mechanisms based on physiologic disturbances caused by cardiac surgery were thought to be responsible for POCD. Although numerous studies evaluated the neurologic complications after cardiac surgery, the exact pathophysiology of POCD after cardiac surgery has not been clearly determined. ${ }^{21}$ Some previous studies described the potential interactions between $\mathrm{AD}$ and POCD, $8,12,14,16,17,22$ and it was found that GDNF 
TABLE 2. Clinical features of non-postoperative cognitive dysfunction group and postoperative cognitive dysfunction group

\begin{tabular}{|c|c|c|c|c|}
\hline Clinical features & Total $(\mathbf{n}=\mathbf{8 0})$ & Non-POCD $(n=42)$ & $\operatorname{POCD}(\mathbf{n}=38)$ & $P$ value \\
\hline Age (y) & $56.7 \pm 5.3$ & $55.6 \pm 4.6$ & $57.8 \pm 5.8$ & .060 \\
\hline \multicolumn{5}{|l|}{ Sex } \\
\hline Male & $36(100.0 \%)$ & $21(58.3 \%)$ & $15(41.7 \%)$ & .345 \\
\hline Female & $44(100.0 \%)$ & $21(47.7 \%)$ & $23(52.3 \%)$ & \\
\hline BMI $\left(\mathrm{kg} / \mathrm{m}^{2}\right)$ & $26.3 \pm 1.4$ & $26.2 \pm 1.4$ & $26.3 \pm 1.4$ & .775 \\
\hline \multicolumn{5}{|l|}{ Education } \\
\hline Lower than middle school & $52(100.0 \%)$ & $18(34.6 \%)$ & $34(65.4 \%)$ & $<.001$ \\
\hline Higher than middle school & $28(100.0 \%)$ & $24(85.7 \%)$ & $4(14.3 \%)$ & \\
\hline \multicolumn{5}{|l|}{ ASA $>$ II } \\
\hline No & $73(100.0 \%)$ & $39(53.4 \%)$ & $34(46.6 \%)$ & .89 \\
\hline Yes & $7(100.0 \%)$ & $3(42.9 \%)$ & $4(57.1 \%)$ & \\
\hline \multicolumn{5}{|l|}{ Arrhythmia } \\
\hline No & $72(100.0 \%)$ & $37(88.1 \%)$ & $35(92.1 \%)$ & .823 \\
\hline Yes & $8(100.0 \%)$ & $5(11.9 \%)$ & $3(7.9 \%)$ & \\
\hline \multicolumn{5}{|l|}{ Hypertension } \\
\hline No & $58(100.0 \%)$ & $33(78.6 \%)$ & $25(65.8 \%)$ & .201 \\
\hline Yes & $22(100.0 \%)$ & $9(21.4 \%)$ & $13(34.2 \%)$ & \\
\hline \multicolumn{5}{|l|}{ Diabetes } \\
\hline No & $60(100.0 \%)$ & $33(78.6 \%)$ & $27(71.1 \%)$ & .438 \\
\hline Yes & $20(100.0 \%)$ & $9(21.4 \%)$ & $11(28.9 \%)$ & \\
\hline \multicolumn{5}{|l|}{ Alcoholism } \\
\hline No & $58(100.0 \%)$ & $28(66.7 \%)$ & $30(78.9 \%)$ & .219 \\
\hline Yes & $22(100.0 \%)$ & $14(33.3 \%)$ & $8(21.1 \%)$ & \\
\hline \multicolumn{5}{|l|}{ Chronic smoking } \\
\hline No & $60(100.0 \%)$ & $30(71.4 \%)$ & $30(78.9 \%)$ & .438 \\
\hline Yes & $20(100.0 \%)$ & $12(28.6 \%)$ & $8(21.1 \%)$ & \\
\hline \multicolumn{5}{|l|}{ NYHA classification >I } \\
\hline No & $64(100.0 \%)$ & $34(53.1 \%)$ & $30(46.9 \%)$ & .823 \\
\hline Yes & $16(100.0 \%)$ & $8(50.0 \%)$ & $8(50.0 \%)$ & \\
\hline \multicolumn{5}{|l|}{ Valve replacement } \\
\hline Mitral valve & $20(100.0 \%)$ & $12(60.0 \%)$ & $8(40.0 \%)$ & .556 \\
\hline Double valve & $45(100.0 \%)$ & $21(46.7 \%)$ & $24(53.3 \%)$ & \\
\hline Aortic valve & $14(100.0 \%)$ & $8(57.1 \%)$ & $6(42.9 \%)$ & \\
\hline Duration of on-pump (min) & $126.4 \pm 35.0$ & $132.0 \pm 37.6$ & $120.3 \pm 31.2$ & .136 \\
\hline Aorta crossclamp time (min) & $84.3 \pm 29.4$ & $91.2 \pm 31.4$ & $76.6 \pm 25.3$ & .026 \\
\hline Duration of recovering temperature (min) & $20.6 \pm 4.8$ & $20.6 \pm 3.8$ & $20.6 \pm 5.8$ & .015 \\
\hline Duration of surgery (min) & $204.0 \pm 29.9$ & $210.7 \pm 31.3$ & $196.6 \pm 26.8$ & .034 \\
\hline \multicolumn{5}{|l|}{ Blood transfusion of at least $400 \mathrm{~mL}$} \\
\hline No & $61(100.0 \%)$ & $37(60.7 \%)$ & $24(39.3 \%)$ & .009 \\
\hline Yes & $19(100.0 \%)$ & $5(26.3 \%)$ & $14(73.7 \%)$ & \\
\hline Midazolam (mg) & $10.6 \pm 3.2$ & $11.6 \pm 3.3$ & $9.5 \pm 2.8$ & .004 \\
\hline Lowest body temperature $\left({ }^{\circ} \mathrm{C}\right)$ & $28.7 \pm 0.9$ & $28.8 \pm 1.0$ & $28.7 \pm 0.8$ & .592 \\
\hline Cardioplegia frequency & $2.1 \pm 0.8$ & $2.3 \pm 0.9$ & $2.0 \pm 0.7$ & .095 \\
\hline Baseline MMSE & $27(25,30)$ & $28(26,30)$ & $26(25,27)$ & $<.001$ \\
\hline Baseline DST & $15(11,16)$ & $15(12,16)$ & $14(11,16)$ & .014 \\
\hline Baseline SDMT & $33(25,35)$ & $32(25,35)$ & $34(25,35)$ & .269 \\
\hline Baseline TMT-A & $41(35,42)$ & $41(35,42)$ & $40(35,42)$ & .266 \\
\hline
\end{tabular}


TABLE 2. Continued

\begin{tabular}{|c|c|c|c|c|}
\hline Clinical features & Total $(\mathbf{n}=\mathbf{8 0})$ & Non-POCD $(n=42)$ & $\operatorname{POCD}(\mathbf{n}=38)$ & $P$ value \\
\hline Baseline CDT & & & & .081 \\
\hline 2 & $26(100.0 \%)$ & $10(38.5 \%)$ & $16(61.5 \%)$ & \\
\hline 3 & $54(100.0 \%)$ & $32(59.3 \%)$ & $22(40.7 \%)$ & \\
\hline \multicolumn{5}{|l|}{ GDNF } \\
\hline $\mathrm{T} 1$ & $227.7 \pm 26.6$ & $225.9 \pm 26.0$ & $229.7 \pm 27.5$ & .528 \\
\hline T1-T2 & $13.9 \pm 50.5$ & $4.2 \pm 40.6$ & $24.6 \pm 58.1$ & .081 \\
\hline T1-T3 & $51.1 \pm 38.9$ & $28.5 \pm 25.6$ & $76.1 \pm 35.7$ & $<.001$ \\
\hline T1-T4 & $72.3 \pm 46.1$ & $40.3 \pm 28.8$ & $107.7 \pm 34.2$ & $<.001$ \\
\hline
\end{tabular}

POCD, Postoperative cognitive dysfunction; BMI, body mass index; ASA, American Society of Anesthesiology; NYHA, New York Heart Association; MMSE, Mini-Mental State Examination; DST, Digit Span Test; SDMT, Symbol Digit Modalities Test; TMT-A, Trail Making Test A; CDT, Clock Drawing Test; GDNF, glial cell line-derived neurotrophic factor; $T 1$, before surgery; $T 2,1$ day after surgery; $T 3,2$ days after surgery; $T 4,7$ days after surgery.

levels are altered in the cerebrospinal fluid (CSF) and serum of patients with $\mathrm{AD}{ }^{16,17}$ In the present study, it was found that the average GDNF levels at 2 and 7 days after surgery in the POCD group were lower than in the non-POCD group at the same time points. These results, combined with previous results on $\mathrm{AD}$, suggest the involvement of GDNF in POCD. GDNF has been shown to promote development, differentiation, and protection of central nervous system neurons and is thought to play an important role in various neuropsychiatric disorders. ${ }^{23}$ Zhang and colleagues ${ }^{24,25}$ showed that low serum GDNF levels could be involved in the pathophysiology of major depressive disorder. Lin and Tseng ${ }^{26}$ described blood GDNF levels as a biomarker of depression. Depletion of GDNF seems to be associated with the pathology and symptoms of diseases. such as AD. ${ }^{26}$ The serum levels of GDNF were shown to be lower in patients with $\mathrm{AD}$ than in healthy controls. ${ }^{16}$ Zhang and colleagues $^{24,25}$ showed that antidepressant treatment increases GDNF levels in patients with major depressive disorder. Furthermore, electroconvulsive therapy increases GDNF serum levels in patients with drug-resistant depression. ${ }^{24}$ Therefore, GDNF has been studied as a therapeutic option for neurodegeneration. ${ }^{22}$ Furthermore, it has been reported that $3 \times \mathrm{TgAD}$ mice (in which GNDF levels are downregulated) subjected to 6 months of GDNF overexpression using recombinant lentiviral vectors showed improvements in learning and memory. ${ }^{27}$ This GDNF neuroprotective effect induced a potent upregulation of BDNF, indicating

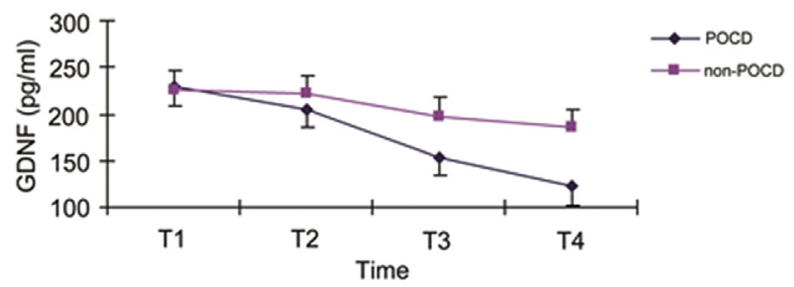

FIGURE 1. Decrease in GDNF levels in each group at different times. T1-4: before and 1, 2, and 7 days after surgery. GDNF, Glial cell line-derived neurotrophic factor; $P O C D$, postoperative cognitive dysfunction; $T 1$, before surgery; $T 2,1$ day after surgery; $T 3,2$ days after surgery; $T 4,7$ days after surgery. that, together, these factors may be important for preventing neuronal atrophy and degeneration. ${ }^{28}$ The present study evaluated serum GDNF levels, but GDNF exerts its effects in the brain. Recent studies showed that CSF levels of GDNF were associated with neuropathic pain in patients undergoing spinal cord stimulation. ${ }^{29}$ Patients with AD have higher levels CSF levels of GDNF, probably because of an adaptive process in the impaired brain. ${ }^{17}$ Patients with amyotrophic lateral sclerosis have higher CSF levels of GDNF than controls. ${ }^{30}$ Therefore, future studies should evaluate serum and CSF GDNF levels. The role of the blood-brain barrier should be investigated.

The present study showed that altered GDNF levels in the peripheral blood after surgery showed a good correlation with International Study of Postoperative Cognitive Dysfunction-defined POCD. In the present study, the perioperative factors (duration of aorta crossclamping, duration of surgery, and amount of transfused blood) were significantly different between the POCD and non-POCD groups, whereas cardiovascular risk factors such as arrhythmia, hypertension, diabetes mellitus, chronic smoking, and alcoholism were not associated with POCD. In the multivariable logistic regression analysis, age, $\triangle \mathrm{GDNF}(\mathrm{T} 1-\mathrm{T} 4)$, and MMSE score (T1) were independently associated with POCD. Most important, using receiver operating characteristic analyses, it was found that $\Delta \mathrm{GDNF}(\mathrm{T} 1-\mathrm{T} 3)$ and $\Delta \mathrm{GDNF}(\mathrm{T} 1-\mathrm{T} 4)$ were predictors of POCD.

TABLE 3. Postoperative neurocognitive outcomes of non-postoperative cognitive dysfunction group and postoperative cognitive dysfunction group

\begin{tabular}{lccc}
\hline $\begin{array}{c}\text { Cognitive } \\
\text { function scores }\end{array}$ & POCD $(\mathbf{n}=\mathbf{3 8})$ & Non-POCD $(\mathbf{n}=\mathbf{4 2})$ & $\boldsymbol{P}$ value \\
\hline MMSE scores & $25.1 \pm 0.8$ & $26.4 \pm 1.3$ & $<.001$ \\
DST scores & $15.8 \pm 1.3$ & $14.9 \pm 1.1$ & $<.001$ \\
CDT scores & $1.7 \pm 0.7$ & $2.6 \pm 0.5$ & $<.001$ \\
SDMT scores & $33.9 \pm 2.5$ & $33.2 \pm 2.4$ & .218 \\
TMT-A scores & $40.6 \pm 2.1$ & $41.2 \pm 1.7$ & .151 \\
\hline
\end{tabular}

POCD, Postoperative cognitive dysfunction; MMSE, Mini-Mental $\quad$ State Examination; $D S T$, Digit Span Test; $C D T$, Clock Drawing Test; SDMT, Symbol Digit Modalities Test; TMT-A, Trail Making Test A. 


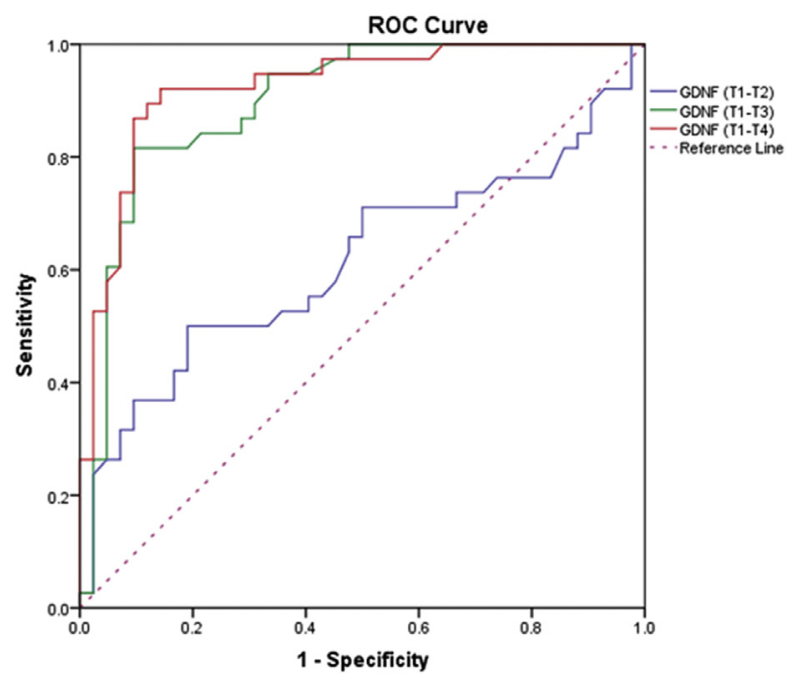

FIGURE 2. Receiver operating characteristic analysis of the average $\triangle \mathrm{GDNF}$ at $\mathrm{T} 2, \mathrm{~T} 3$, and $\mathrm{T} 4$ compared with $\mathrm{T} 1 . R O C$, Receiver operating characteristic; $G D N F$, glial cell line-derived neurotrophic factor; $T 1$, before surgery; $T 2,1$ day after surgery; $T 3,2$ days after surgery; T4, 7 days after surgery.

The prevalence of reported POCD varies widely 7 days after surgery. ${ }^{31-34}$ These conflicting results may be due to the different populations and different diagnostic tools and physicians' experience. ${ }^{33}$ The incidence of POCD $(47.5 \%)$ in the present study 7 days after surgery was higher than in a comparable study. ${ }^{35}$ In early studies, it was found that education, but not other perioperative factors, was an independent perioperative influential factor for POCD. ${ }^{36-39}$ This association was not observed in the present study, which may be due to the different diagnostic criteria used for POCD, different tested populations, and different surgery types.

\section{Study Limitations}

The sample size was small. In addition, the patients were selected from a single hospital. No data are available on the GDNF levels in the CSF. Because the effect of GDNF is mainly on the central nervous system neurons, future studies should include a complete CSF assessment, including neurotrophic factors and inflammatory markers. The questionnaires assumed that the test-retest values for normal volunteers are the same for postsurgical patients, which is probably not the case because of preoperative anxiety and postoperative pain, intensive care unit stay, and hospitalization. In addition, it was assumed that the preoperative score was obtained without error. Additional studies with a larger sample size and more complete data are necessary to determine the exact contribution of GDNF to POCD.

\section{CONCLUSIONS}

The present study suggests that the incidence of POCD in patients undergoing valve replacement surgery is $47.5 \%$.
The perioperative GDNF levels of patients with POCD were lower than those of patients without POCD. GDNF levels along with multiple perioperative influential factors could be an effective predictor for the occurrence of POCD. The present study suggests a potentially important role of decreased GDNF levels in the development of POCD and provides a new insight into the diagnosis and possible treatment targets for POCD.

\section{Conflict of Interest Statement}

Authors have nothing to disclose with regard to commercial support.

The authors thank all of the patients who participated in this study and made this work possible.

\section{References}

1. Marijon E, Mirabel M, Celermajer DS, Jouven X. Rheumatic heart disease. Lancet. 2012;379:953-64.

2. Ghaffary S, Hajhossein Talasaz A, Ghaeli P, Karimi A, Salehiomran A, Hajighasemi A, et al. Association between perioperative parameters and cognitive impairment in post-cardiac surgery patients. J Tehran Heart Cent. 2015; 10:85-92.

3. Evered L, Silbert B, Scott DA, Ames D, Maruff P, Blennow K. Cerebrospinal fluid biomarker for alzheimer disease predicts postoperative cognitive dysfunction. Anesthesiology. 2016;124:353-61.

4. Hanning CD. Postoperative cognitive dysfunction. Br J Anaesthes. 2005;95:82-7.

5. Hogan AM, Shipolini A, Brown MM, Hurley R, Cormack F. Fixing hearts and protecting minds: a review of the multiple, interacting factors influencing cognitive function after coronary artery bypass graft surgery. Circulation. 2013;128:162-71.

6. Xu T, Bo L, Wang J, Zhao Z, Xu Z, Deng X, et al. Risk factors for early postoperative cognitive dysfunction after non-coronary bypass surgery in Chinese population. J Cardiothorac Surg. 2013;8:204.

7. Kim S, Brooks AK, Groban L. Preoperative assessment of the older surgical patient: honing in on geriatric syndromes. Clin Interv Aging. 2015;10:13-27.

8. Groen JA, Banayan D, Gupta S, Xu S, Bhalerao S. Treatment of delirium following cardiac surgery. J Card Surg. 2012;27:589-93.

9. Krzych LJ, Wybraniec MT, Krupka-Matuszczyk I, Skrzypek M, Bolkowska A, Wilczynski M, et al. Detailed insight into the impact of postoperative neuropsychiatric complications on mortality in a cohort of cardiac surgery subjects: a 23,000-patient-year analysis. J Cardiothorac Vasc Anesthes. 2014;28:448-57.

10. Newman MF, Grocott HP, Mathew JP, White WD, Landolfo K, Reves JG, et al. Report of the substudy assessing the impact of neurocognitive function on quality of life 5 years after cardiac surgery. Stroke. 2001;32:2874-81.

11. Newman S, Stygall J, Hirani S, Shaefi S, Maze M. Postoperative cognitive dysfunction after noncardiac surgery: a systematic review. Anesthesiology. 2007; 106:572-90.

12. Monk TG, Weldon BC, Garvan CW, Dede DE, van der Aa MT, Heilman KM, et al. Predictors of cognitive dysfunction after major noncardiac surgery. Anesthesiology. 2008;108:18-30.

13. Ritchie K, Carriere I, Ritchie CW, Berr C, Artero S, Ancelin ML. Designing prevention programmes to reduce incidence of dementia: prospective cohort study of modifiable risk factors. BMJ. 2010;341:c3885.

14. Hua F, Yang C, Zhu B. Leptin: new hope for the treatment of post-operative cognitive dysfunction? Med Sci Monit. 2014;20:866-8.

15. Lin LF, Doherty DH, Lile JD, Bektesh S, Collins F. GDNF: a glial cell line-derived neurotrophic factor for midbrain dopaminergic neurons. Science. 1993;260:1130-2.

16. Straten G, Saur R, Laske C, Gasser T, Annas P, Basun H, et al. Influence of lithium treatment on GDNF serum and CSF concentrations in patients with early Alzheimer's disease. Curr Alzheimer Res. 2011;8:853-9.

17. Straten G, Eschweiler GW, Maetzler W, Laske C, Leyhe T. Glial cell-line derived neurotrophic factor (GDNF) concentrations in cerebrospinal fluid and serum of patients with early Alzheimer's disease and normal controls. J Alzheimers Dis. 2009; 18:331-7. 
18. Rasmussen LS, Larsen K, Houx P, Skovgaard LT, Hanning CD, Moller JT, et al. The assessment of postoperative cognitive function. Acta Anaesthesiol Scand. 2001; 45:275-89.

19. Silbert BS, Evered LA, Scott DA. Incidence of postoperative cognitive dysfunction after general or spinal anaesthesia for extracorporeal shock wave lithotripsy. Br J Anaesthes. 2014;113:784-91.

20. Okragly AJ, Haak-Frendscho M. An acid-treatment method for the enhanced detection of GDNF in biological samples. Exp Neurol. 1997;145(2 Pt 1):592-6.

21. van Harten AE, Scheeren TW, Absalom AR. A review of postoperative cognitive dysfunction and neuroinflammation associated with cardiac surgery and anaesthesia. Anaesthesia. 2012;67:280-93.

22. Arora SS, Gooch JL, Garcia PS. Postoperative cognitive dysfunction, Alzheimer's disease, and anesthesia. Int J Neurosci. 2014;124:236-42.

23. Allen SJ, Watson JJ, Shoemark DK, Barua NU, Patel NK. GDNF, NGF and BDNF as therapeutic options for neurodegeneration. Pharmacol Ther. 2013; 138:155-75.

24. Zhang X, Zhang Z, Sha W, Xie C, Xi G, Zhou H, et al. Electroconvulsive therapy increases glial cell-line derived neurotrophic factor (GDNF) serum levels in patients with drug-resistant depression. Psychiatry Res. 2009;170:273-5.

25. Zhang X, Zhang Z, Xie C, Xi G, Zhou H, Zhang Y, et al. Effect of treatment on serum glial cell line-derived neurotrophic factor in depressed patients. Prog $\mathrm{Neu}$ ropsychopharmocol Biol Psychiatry. 2008;32:886-90.

26. Lin PY, Tseng PT. Decreased glial cell line-derived neurotrophic factor levels in patients with depression: a meta-analytic study. J Psychiatr Res. 2015;63:20-7.

27. Revilla S, Sunol C, Garcia-Mesa Y, Gimenez-Llort L, Sanfeliu C, Cristofol R. Physical exercise improves synaptic dysfunction and recovers the loss of survival factors in 3xTg-AD mouse brain. Neuropharmacology. 2014;81:55-63.

28. Revilla S, Ursulet S, Alvarez-Lopez MJ, Castro-Freire M, Perpina U, GarciaMesa Y, et al. Lenti-GDNF gene therapy protects against Alzheimer's diseaselike neuropathology in 3xTg-AD mice and MC65 cells. CNS Neurosci Ther. 2014;20:961-72.

29. McCarthy KF, McCrory C. Cerebrospinal fluid levels of glial cell-derived neurotrophic factor correlate with spinal cord stimulation frequency in patients with neuropathic pain: a preliminary report. Spinal Cord. 2014;52(Suppl 2): S8-10.
30. Grundstrom E, Lindholm D, Johansson A, Blennow K, Askmark H. GDNF but not BDNF is increased in cerebrospinal fluid in amyotrophic lateral sclerosis Neuroreport. 2000;11:1781-3.

31. Sauer AM, Kalkman C, van Dijk D. Postoperative cognitive decline. J Anesth 2009;23:256-9.

32. McDonagh DL, Mathew JP, White WD, Philips-Bute B, Laskowitz DT, Podgoreanu MV, et al. Cognitive function after major noncardiac surgery, apolipoprotein E4 genotype, and biomarkers of brain injury. Anesthesiology. 2010; 112:852-9.

33. Krenk L, Rasmussen LS, Kehlet H. New insights into the pathophysiology of postoperative cognitive dysfunction. Acta Anaesthesiol Scand. 2010;54:951-6.

34. Johnson T, Monk T, Rasmussen LS, Abildstorm H, Houx P, Korttila K, et al. Postoperative cognitive dysfunction in middle-aged patients. Anesthesiology. 2002; 96:1351-7.

35. Li YC, Xi CH, An YF, Dong WH, Zhou M. Perioperative inflammatory response and protein S-100beta concentrations - relationship with postoperative cognitive dysfunction in elderly patients. Acta Anaesthesiol Scand. 2012;56:595-600.

36. Cerejeira J, Batista P, Nogueira V, Vaz-Serra A, Mukaetova-Ladinska EB. The stress response to surgery and postoperative delirium: evidence of hypothalamic-pituitry-adrenal axis hyperresponsiveness and decreased suppression of the GH/IGF-1 Axis. J Geriatr Psychiatr Neurol. 2013;26:185-94.

37. Goto T, Maekawa K. Cerebral dysfunction after coronary artery bypass surgery J Anesth. 2014;28:242-8

38. Tully PJ, Baker RA. The reliable change index for assessment of cognitive dysfunction after coronary artery bypass graft surgery. Ann Thorac Surg. 2013 96:1529.

39. Ng LL, Sandhu JK, Narayan H, Quinn PA, Squire IB, Davies JE, et al. Proenkephalin and prognosis after acute myocardial infarction. J Am Coll Cardiol. 2014; 63:280-9.

Key Words: diagnosis, glial cell line-derived neurotrophic factor, postoperative cognitive dysfunction, predictor, valve replacement cardiac surgery 


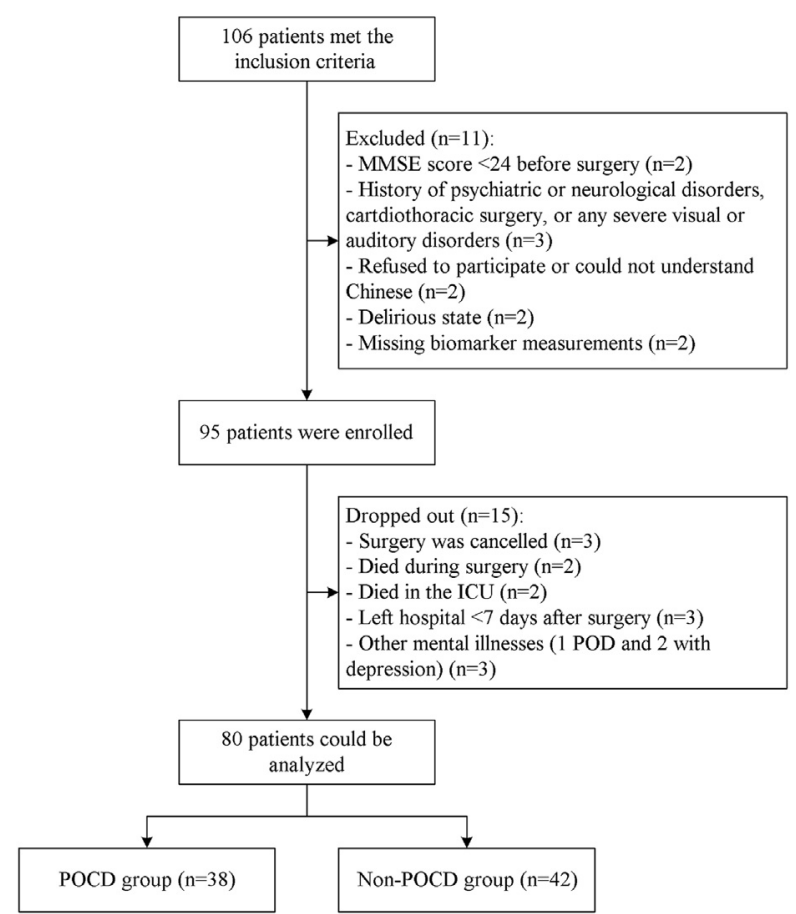

FIGURE E1. Patient flowchart. MMSE, Mini-Mental State Examination; $I C U$, intensive care unit; $P O D$, postoperative delirium; $P O C D$, postoperative cognitive dysfunction.

TABLE E1. Results of multifactor logistic-regression analysis

\begin{tabular}{lccc}
\hline Changed GDNF & Adjusted OR* & OR 95\% CI & $\boldsymbol{P}$ value \\
\hline$\triangle$ GDNF (T1-T2) & 1.008 & $(1.027-1.093)$ & .108 \\
$\triangle$ GDNF (T1-T3) & 1.060 & $(1.027-1.093)$ & $<.001$ \\
$\triangle$ GDNF (T1-T4) & 1.052 & $(1.026-1.078)$ & $<.001$ \\
\hline
\end{tabular}

$O R$, Odds ratio; $C I$, confidence interval; GDNF, glial cell line-derived neurotrophic factor; $T 1$, before surgery; $T 2,1$ day after surgery; $T 3,2$ days after surgery; T4, 7 days after surgery. *Factors $P<.05$ were adjusted, including education, aorta crossclamp time, duration of surgery, blood transfusion of at least $400 \mathrm{~mL}$, and midazolam. 